\title{
Polymorphism and Genetic Relationships among Tea Genotypes from Turkey Revealed by Amplified Fragment Length Polymorphism Markers
}

\author{
Salih Kafkas ${ }^{1}$ \\ Department of Horticulture, Faculty of Agriculture, University of Çukurova, 01330, Adana, Turkey \\ Sezai Ercişli \\ Department of Horticulture, Faculty of Agriculture, Ataturk University 25240, Erzurum, Turkey \\ Yıldız Doğan \\ Department of Horticulture, Faculty of Agriculture, University of Çukurova, 01330, Adana, Turkey
}

Yaşar Ertürk

Ispir Hamza Polat Vocational School, Department of Horticulture, Ataturk University 25900, Ispir, Erzurum, Turkey

\author{
Ayhan Haznedar and Remzi Sekban \\ Ministry of Agriculture, Ataturk Tea and Horticulture Research Institute, 55100 Rize, Turkey
}

Additional INDEX words. similarity, Camellia sinensis, PCoA, UPGMA

\begin{abstract}
Individuals in most countries around the world drink tea (Camellia sinensis). Tea drinking has attained ceremonial status in many places as a social and medicinal beverage. Although tea is of great importance in Turkey's economy, little is known about the pattern of genetic variation among the various tea genotypes grown in Turkey. A total of 32 tea genotypes found at the Ataturk Tea and Horticulture Research Institute in the eastern Black Sea region of Turkey were sampled. Fluorescent dye amplified fragment length polymorphism (AFLP) markers and capillary electrophoresis were applied for molecular characterization. The AFLP analysis with six primer combinations generated 835 fragments of which 567 were polymorphic, corresponding to $69.8 \%$ polymorphism. Resolving powers of the AFLP primers ranged from 62.6 to 81.9, yielding a total of 437.8; the polymorphic information content (PIC) ranged from 0.76 to 0.83 , with an average of 0.79 . Genetic similarity values ranged from 0.68 to 0.92 , with an average of 0.76 . The dendrogram derived by unweighted pair group method with arithmetic mean algorithm (UPGMA) and principal coordinate analysis $(\mathrm{PCOA})$ revealed that all tea genotypes could be clearly divided into four distinct clusters. The results of this study will provide valuable information to the tea cultivar breeding program for the purpose of parental selection.
\end{abstract}

Tea belongs to family Theaceace, genus Camellia, section Thea and usually involves one species (Camellia sinensis), including two or three botanical varieties: $C$. sinensis var. assamica, C. sinensis var. pubilimba (Chen et al., 2000), and sometimes C. sinensis var. kucha (Chang, 1984). China is currently the foremost producer, consumer, and exporter of commercial tea (especially green and oolong tea), while India, Kenya, Sri Lanka, and Turkey are the largest producers of black tea. During the last decade, the average world yield increased $25 \%$, which was largely attributed to the widespread replacement of the diverse local seedling populations with improved and uniform clonally propagated tea cultivars in many countries (Yao et al., 2008).

Although tea plants were first introduced to Turkey in the 1920s, the first plantations were established in the Black Sea region during the 1940s. The tea industry in Turkey has developed very quickly and now Turkey is an important teaproducing country, ranking sixth in the world with annual production of 202,000 $\mathrm{t}$ (Ercisli et al., 2008; Food and Agricultural Organization of the United Nations, 2007). Tea is an econom-

Received for publication 9 Mar. 2009. Accepted for publication 19 June 2009. ${ }^{1}$ Corresponding author. E-mail: skafkas@cu.edu.tr. ically valuable plant for the eastern Black Sea region of Turkey and a means of subsistence for more than 200,000 farmers and 1 million people. The main tea-producing area in Turkey is the Rize Province, which supplies 74\% of Turkey's production and $95 \%$ of the agricultural fields in this province are allocated exclusively to tea cultivation (Altindal and Balta, 2002).

In Turkey, most of the tea plantations were established by using seeds; continuous seed propagation has produced populations with different yield and quality properties, reflecting wide genetic variation. Recently, clonal selection studies were conducted in the Black Sea region and several promising tea clones such as 'Tuglali-10', 'Derepazari-7', and 'Pazar-20' have been identified (Erturk et al., 2008; Oksuz, 1987).

Previously, clonal identification of tea clones in Turkey has involved using morphological and biochemical descriptors (Oksuz, 1987). However, as in many out-crossing plants, tea is highly heterozygous, with most of its morphological and biochemical traits showing continuous variation and high plasticity. In addition, most of the morphological and biochemical traits are influenced by environmental factors (Ariyarathna and Gunasekare, 2006).

Knowledge of genetic diversity among the available tea germplasm is an important prerequisite for future breeding and 
crop improvement programs. More recently, attention has been focused on the use of different DNA molecular markers to discriminate among tea germplasms such as restriction fragment length polymorphism [RFLP (Kaundun and Matsumoto, 2003; Matsumoto et al., 2002)], randomly amplified polymorphic DNA [RAPD (Beris et al., 2005; Chen and Yamaguchi, 2005; Chen et al., 2005; Kaundun et al., 2000; Kaundun and Park, 2002; Park et al., 2002; Wachira et al., 1995)], intersimple sequence repeat [ISSR (Mondal, 2002; Thomas et al., 2006; Yao et al., 2008)], amplified fragment length polymorphism [AFLP (Balasaravanan et al., 2003; Karthigeyan et al., 2008; Lee et al., 2003; Paul et al., 1997)], and simple sequence repeat [SSR (Hung et al., 2008; Ohsako et al., 2008)].

Among PCR-based molecular markers, AFLP is a highly reproducible multilocus marker system developed by Vos et al. (1995). This method has several advantages over previously introduced methods such as RAPDs and ISSRs, and has been extensively used for a wide range of plant species. High levels of polymorphism and high degrees of discriminative capacity are the main advantages of AFLPs used for closely related genotypes.

Previously, only five Turkish tea genotypes were characterized with the RAPD method (Beris et al., 2005). Initial reports in tea (Devarumath et al., 2002; Wachira et al., 2001) confirmed the superiority of AFLP markers over RAPDs. The rate of polymorphism detected per reaction in AFLP is much higher than that revealed by RFLPs or RAPDs due to the number of loci sampled in a single assay. In the present study, AFLP was used to determine genetic relationships among 32 tea genotypes from Turkey to provide valuable information for parental selection in advanced tea breeding programs.

\section{Materials and Methods}

Plant materials. Thirty-two tea genotypes originating from the Rize and Trabzon provinces of Turkey were used in the present study. These genotypes were previously selected for their better characteristics than others and the fact that they were vegetatively propagated, and they were then planted in the Ataturk Tea and Horticulture Research Institute in the eastern Black Sea region of Turkey. The plant materials and some of their morphological characteristics are given in Table 1.

DNA EXTRACTION AND AFLP PROCEDUREs. Genomic DNA was extracted from leaf tissue by the CTAB method of Doyle and Doyle (1987) with minor modifications (Kafkas et al., 2006). Concentrations of extracted DNA were measured by using Qubit fluorometer (Invitrogen, Carlsbad, CA) and were diluted to $50 \mathrm{ng} \cdot \mu \mathrm{L}^{-1}$ for AFLP reactions.

Details of AFLP assay, adapter and primer sequences, PCR conditions for preselective and selective amplifications, and

Table 1. Tea genotypes characterized by AFLP analysis in this study, their province of origin in the Black Sea region of Turkey, internode length, mature leaf color, leaf size, leaf shape, and leaf pubescence.

\begin{tabular}{|c|c|c|c|c|c|c|}
\hline Genotype & Province of origin & Internode length & Mature leaf color & Leaf size & Leaf shape & Leaf pubescence \\
\hline Ardesen & Rize & Intermediate & Yellow green & Medium & Elliptical & Intermediate \\
\hline Derepazari-7 & Rize & Long & Yellow green & Very large & Oblong & Dense \\
\hline Enstitü-9 & Rize & Intermediate & Yellow green & Medium & Elliptical & Intermediate \\
\hline Enstitu-61 & Rize & Intermediate & Yellow green & Large & Elliptical & Sparse \\
\hline Fener-3 & Rize & Intermediate & Grayed-green & Medium & Elliptical & Dense \\
\hline Guneysu-26 & Rize & Intermediate & Medium green & Large & Oblong & Intermediate \\
\hline Hamzabey & Rize & Intermediate & Grayed-green & Large & Oblong & Intermediate \\
\hline Hayrat & Trabzon & Intermediate & Yellow green & Medium & Oblong & Intermediate \\
\hline Kalkandere-10 & Rize & Short & Medium green & Medium & Elliptical & Sparse \\
\hline Kalkandere-12 & Rize & Intermediate & Medium green & Small & Elliptical & Intermediate \\
\hline Of-25 & Trabzon & Short & Medium green & Medium & Elliptical & Sparse \\
\hline Of-37 & Trabzon & Short & Medium green & Medium & Elliptical & Intermediate \\
\hline Of-53 & Trabzon & Intermediate & Medium green & Medium & Oblong & Sparse \\
\hline Of-66 & Trabzon & Short & Medium green & Medium & Elliptical & Intermediate \\
\hline Of-264 & Trabzon & Short & Medium green & Small & Elliptical & Intermediate \\
\hline Pazar-14 & Rize & Long & Yellow green & Medium & Oblong & Sparse \\
\hline Pazar-20 & Rize & Long & Yellow green & Medium & Ovate & Sparse \\
\hline Pazar-42 & Rize & Long & Green & Medium & Elliptical & Intermediate \\
\hline Surmene-1 & Trabzon & Long & Yellow green & Medium & Oblong & Intermediate \\
\hline Surmene-6 & Trabzon & Short & Green & Medium & Oblong & Sparse \\
\hline Surmene-24 & Trabzon & Short & Grayed-green & Medium & Elliptical & Sparse \\
\hline
\end{tabular}


selective primer designation were according to Vos et al. (1995) with minor modifications (Kafkas et al., 2008). Genomic DNA was digested with EcoRI/MseI enzyme combination and double-stranded adapters specific to each site were ligated. Preselective amplification was carried out with primers complementary to the adapters with an extra-selective base on each primer (EcoRI-A/MseI-A). Selective amplifications in all genotypes were performed with six primer combinations involving $\mathrm{E}_{\mathrm{AGA}} / \mathrm{M}_{\mathrm{ACT}}, \mathrm{E}_{\mathrm{AGA}} / \mathrm{M}_{\mathrm{AGA}}, \mathrm{E}_{\mathrm{AGA}} / \mathrm{M}_{\mathrm{ATC}}, \mathrm{E}_{\mathrm{AGT}} /$ $\mathrm{M}_{\mathrm{AGA}}, \mathrm{E}_{\mathrm{AGT}} / \mathrm{M}_{\mathrm{AGT}}$, and $\mathrm{E}_{\mathrm{AGT}} / \mathrm{M}_{\mathrm{ATC}}$ after initial screening of 24 primer pairs in eight genotypes. The adapter sequences, preselective amplification primers, and selective primers are listed in Table 2. Fragments were resolved using capillary electrophoresis on an ABI 3130xl Genetic Analyzer [Applied Biosystems (ABI), Foster City, CA] with the data collection software 3.0 (ABI). AFLP fragment analysis was performed with GeneScan Analysis Software 4.0 (ABI).

DAta AnAlysis. The ability of the most informative primer pairs to differentiate between the genotypes was assessed by calculating their resolving power (Rp) according to Prevost and Wilkinson (1999) using the formula $\mathrm{Rp}=\sum \mathrm{Ib}$, where $\mathrm{Ib}=1-$ $(2 \times|0.5-\mathrm{p}|)$, and $\mathrm{p}$ is the proportion of the genotypes containing the I band. The PIC of each marker was calculated using $\mathrm{PIC}=1-\sum \mathrm{Pi}^{2}$, where $\mathrm{Pi}$ is the band frequency of the $\mathrm{i}^{\text {th }}$ allele (Smith et al., 1997). A dendrogram was generated using NTSYSpc (version 2.11V; Exeter Software, Setauket, NY) (Rohlf, 2004) based on the unweighted pair group method with arithmetic mean cluster analysis (UPGMA). Jaccard coefficients were calculated for all pairwise comparisons among the 32 tea genotypes using the same program. The similarity matrix data were also subjected to principal coordinate analysis (PCoA) using the NTSYSpc program. The representativeness of the dendrogram was evaluated by estimating cophenetic correlation for the dendrogram and comparing it with the similarity matrix using Mantel's matrix correspondence test (Mantel, 1967).

\section{Results and Discussion}

LEVEL OF POLYMORPHISM AND DISCRIMINATING CAPACITY OF THE AFLP PRIMER PAIRS. The six primer combinations used to characterize 32 tea genotypes generated a total of 835 bands (Table 3). The number of bands produced by each primer combination ranged from $110\left(\mathrm{E}_{\mathrm{AGA}} / \mathrm{M}_{\mathrm{ATC}}\right)$ to $175\left(\mathrm{E}_{\mathrm{AGA}} /\right.$ $\mathrm{M}_{\mathrm{AGA}}$ ), with an average of 139 bands. Of 835 bands, 567 were polymorphic, with $69.8 \%$ polymorphism. The percentage of polymorphic bands varied considerably among the primer combinations. For example, the highest polymorphism ratio $(87.3 \%)$ was obtained with the $\mathrm{E}_{\mathrm{AGA}} / \mathrm{M}_{\mathrm{ATC}}$ primer pair, while the lowest was observed with the $\mathrm{E}_{\mathrm{AGA}} / \mathrm{M}_{\mathrm{AGA}}(47.4 \%)$ primer pair.

The present results suggested that the AFLP analysis successfully differentiated the tea genotypes; we confirmed that AFLP is a powerful marker system. Previously, AFLP markers were used to characterize various tea germplasms. Paul et al. (1997) studied 32 tea genotypes from India and Kenya using five AFLP primer pairs that generated an average of 73 amplification products and 15 polymorphic bands per primer combination. Balasaravanan et al. (2003) used three AFLP primer pairs to study the diversity assessment of 49 south Indian tea cultivars and obtained 1555 unambiguous polymorphic amplified fragments with an average of 518.3 polymorphic loci per primer pair. The authors indicated that AFLP is a powerful tool among the available genetic fingerprinting techniques, and it can be adopted for any kind of tea breeding program. Lee et al. (2003) characterized 37 tea genotypes using 10 AFLP primer pairs in $13 \%$ polyacrylamide gels with ethidium bromide staining. The AFLP primer pairs produced an average of 38.6 bands with $54.1 \%$ polymorphism. Karthigeyan et al. (2008) used three AFLP primer combinations to study genetic diversity among 14 tea genotypes from western Himalaya. Our experiment represents six AFLP primer pairs in the fingerprinting of 32 genotypes from Turkey; the number of bands and their polymorphism rates were higher than observed in previous studies, except the study performed by Balasaravanan et al. (2003). This is an indication of the high degree of polymorphism among the genotypes tested. This supports the observation of Beris et al. (2005) who used RAPD markers in five Turkish tea genotypes and reported a high degree of genetic diversity. Similar or higher polymorphism rates were obtained when the other DNA marker techniques such as ISSR and RAPD were applied to different tea germplasms. These findings

Table 2. Sequences of oligonucleotide adapters, and preselective and selective primers used in AFLP analysis for the characterization of 32 tea genotypes originating from the Trabzon and Rize provinces of Turkey.

\begin{tabular}{|c|c|c|}
\hline Adapter/primer & Code & Sequence $\left(5^{\prime}-3^{\prime}\right)$ \\
\hline \multicolumn{3}{|l|}{ Adapters } \\
\hline \multirow[t]{2}{*}{ EcoRI adapters } & & CTC GTA GAC TGC GTA CC \\
\hline & & AAT TGG TAC GCA GTC TAC \\
\hline MseI adapters & & TAC TCA GGA CTC AT \\
\hline \multicolumn{3}{|c|}{ Preselective amplification primers } \\
\hline EcoRI primer $+\mathrm{A}$ & $\mathrm{E}_{\mathrm{A}}$ & GACTGCGTACCAATTC+A \\
\hline \multicolumn{3}{|c|}{ Selective amplification primers } \\
\hline$E c o \mathrm{RI}+3-\mathrm{AGA}$ & $\mathrm{E}_{\mathrm{AGA}}$ & (6-FAM) GACTGCGTACCAATTC+AGA \\
\hline$E c o$ RI + 3-AGT & $\mathrm{E}_{\mathrm{AGT}}$ & $(V I C)$ GACTGCGTACCAATTC+AGT \\
\hline$M s e \mathrm{I}+3-\mathrm{ACT}$ & $\mathrm{M}_{\mathrm{ACT}}$ & GATGAGTCCTGAGTAA+ACT \\
\hline MseI + 3-AGA & $\mathrm{M}_{\mathrm{AGA}}$ & GATGAGTCCTGAGTAA+AGA \\
\hline$M s e I+3-A G T$ & $\mathrm{M}_{\mathrm{AGT}}$ & GATGAGTCCTGAGTAA+AGT \\
\hline
\end{tabular}


Table 3. Number of total and polymorphic AFLP bands, percentage of polymorphic bands, resolving powers, and polymorphism information content in the DNA fingerprinting of tea genotypes originating from the Trabzon and Rize provinces of Turkey.

\begin{tabular}{lccccc}
\hline $\begin{array}{l}\text { AFLP primer } \\
\text { combination }\end{array}$ & $\begin{array}{c}\text { Total bands } \\
\text { (no.) }\end{array}$ & $\begin{array}{c}\text { Polymorphic bands } \\
\text { (no.) }\end{array}$ & $\begin{array}{c}\text { Polymorphism } \\
\text { (\%) }\end{array}$ & $\begin{array}{c}\text { Resolving } \\
\text { power }\end{array}$ & $\begin{array}{c}\text { Polymorphism } \\
\text { information content }\end{array}$ \\
\hline $\mathrm{E}_{\mathrm{AGA}} / \mathrm{M}_{\mathrm{ACT}}$ & 145 & 119 & 82.1 & 81.9 & 0.83 \\
$\mathrm{E}_{\mathrm{AGA}} / \mathrm{M}_{\mathrm{AGA}}$ & 175 & 83 & 47.4 & 71.1 & 0.75 \\
$\mathrm{E}_{\mathrm{AGA}} / \mathrm{M}_{\mathrm{ATC}}$ & 110 & 96 & 87.3 & 68.3 & 0.81 \\
$\mathrm{E}_{\mathrm{AGT}} / \mathrm{M}_{\mathrm{AGA}}$ & 157 & 100 & 63.7 & 76.4 & 0.78 \\
$\mathrm{E}_{\mathrm{AGT}} / \mathrm{M}_{\mathrm{AGT}}$ & 112 & 90 & 80.4 & 77.5 & 0.76 \\
$\mathrm{E}_{\mathrm{AGT}} / \mathrm{M}_{\mathrm{ATC}}$ & 136 & 79 & 56.1 & 62.6 & 0.79 \\
Total & 835 & 567 & & 437.8 & \\
Mean & 139 & 95 & 69.8 & 73.0 & 0.79 \\
\hline
\end{tabular}

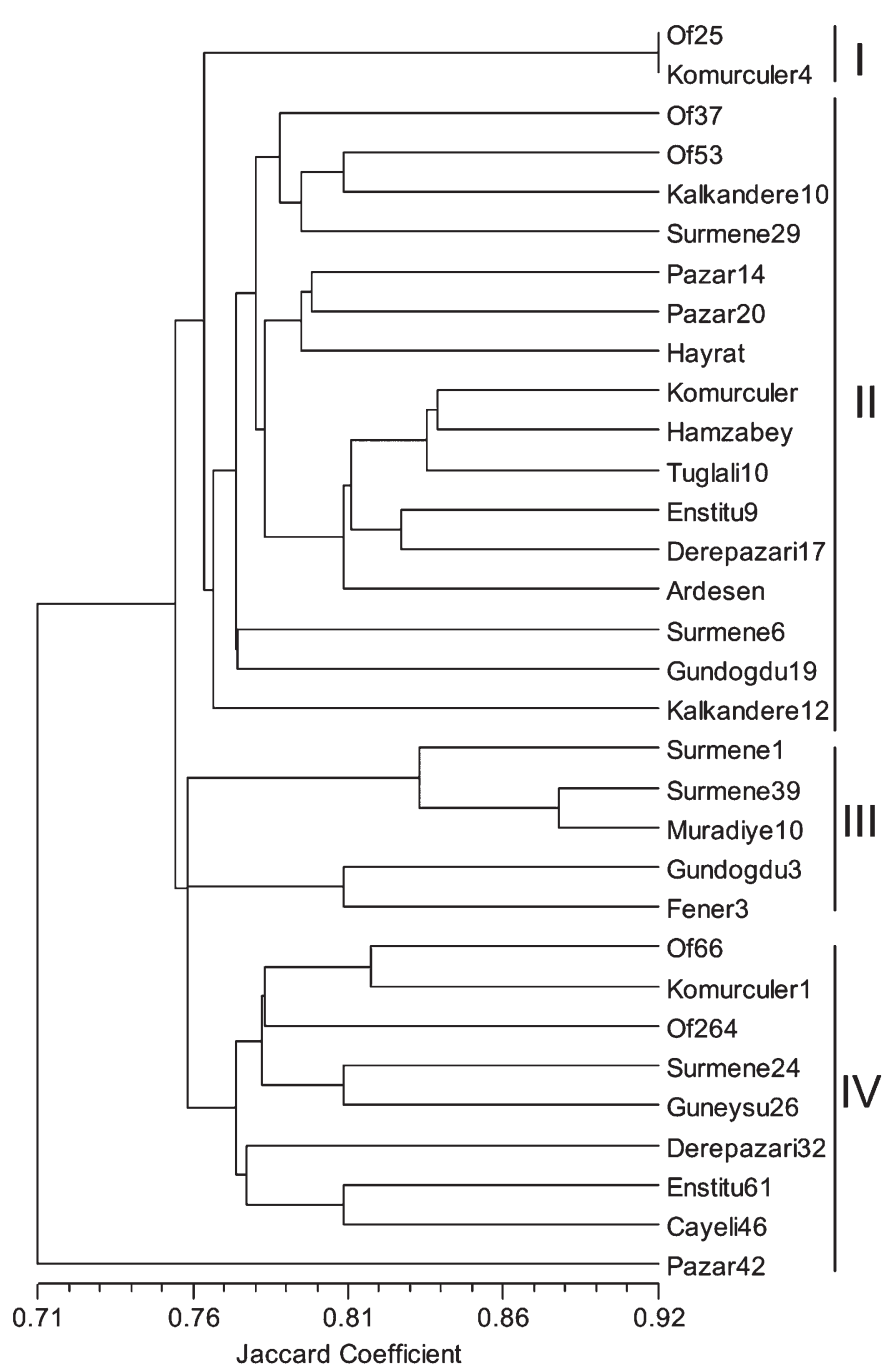

Fig. 1. Dendrogram of 32 tea genotypes, originating from the Trabzon and Rize provinces of Turkey, resulting from the unweighted pair-group method of arithmetic mean cluster analysis based on Jaccard similarity coefficient obtained from 835 AFLP markers ( $r=0.90$ for goodness-of-fit).

are in agreement with the observation that outbreeding woody plants retains considerable genetic variability. On the other hand, Turkish tea clones are accepted as China-type and it was previously shown that China-type teas are the most variable (Paul et al., 1997). Moreover, self-incompatibility and long- term allogamy render the tea plant highly heterogeneous, and consequently yield broad genetic variation (Chen et al., 2005).

Resolving power values of AFLP primer combinations ranged from $62.6\left(\mathrm{E}_{\mathrm{AGT}} / \mathrm{M}_{\mathrm{ATC}}\right)$ to $81.9\left(\mathrm{E}_{\mathrm{AGA}} /\right.$ $\mathrm{M}_{\mathrm{ACT}}$ ), with a total of 437.8 and an average of 73.0. The PIC values of the primer combinations ranged from 0.76 to 0.83 with an average of 0.79 . Yao et al. (2008) used 21 ISSR primers to characterize 48 tea cultivars from China, Kenya, and Japan; the average RP value was 7.4. We obtained average RP values in this study that were about 10 times higher, demonstrating the discriminating capacity of the AFLP primer pairs.

Genetic Relatedness among the tea Genotypes. Genetic similarity values calculated by AFLP data ranged from 0.68 for the most distant cultivars to 0.92 for the closest ones, with an average of 0.76 . The most distant pairs of genotypes were 'Pazar-42'-'Komurculer' and 'Pazar-42'-'Komurculer-4', with a similarity coefficient of 0.68 . The dendrogram obtained from 835 AFLP markers separated all genotypes from each other (Fig. 1). The cophenetic correlation coefficient indicated a correlation of 0.90 between the similarity matrix and the cophenetic matrix, measured by using the UPGMA dendrogram data. The genetic relationships among the 32 genotypes were examined by UPGMA clustering (Fig. 1) and threedimensional plot of PCoA (Fig. 2). Although the UPGMA dendrogram and PCoA divided tea genotypes into four main clusters, there were slight differences between them.

The cluster I included 'Of-25' and 'Komurculer-4' genotypes. These two genotypes are the closest pair of genotypes in this study with a highest similarity coefficient of 0.92 . They had a medium leaf size, an elliptical leaf shape, and sparse leaf pubescence. However, 'Of-25' had short internode length and a green leaf color in contrast to 'Komurculer-4', which had intermediate internode length and a yellow-green leaf color (Table 1). These results may suggest that these two genotypes may have originated from the same seed source.

The cluster II was the largest group, having 16 tea genotypes. In this cluster, three pairs of genotypes had a genetic similarity coefficient of 0.84 ('Hamzabey'-'Komurculer', 'Tuglali-10''Hamzabey', and 'Tuglali-10'-'Komurculer'). According to the PCoA analysis, the cluster II divided into four subclusters: the first one included 'Komurculer' and 'Tuglali-10' genotypes, whereas subcluster II had six genotypes ('Hamzabey', 'Enstitu9', 'Kankandere-10', 'Derepazari-7', 'Ardesen', and 'Of-53'). Subcluster III had 'Hayrat', 'Pazar-20', 'Surmene-29', and 'Gundogdu-19' genotypes, while subcluster IV consists of 'Of37', 'Of-261', 'Surmene-6', and 'Kalkandere-12' genotypes.

There were differences between the dendrogram and PCoA plot in the cluster II and cluster IV (Figs. 1 and 2). The genotype 'Pazar-14' was in the second cluster of the dendrogram, whereas this genotype was in the fourth cluster of PCoA plot. The other difference was in the genotype 'Of-264'. It was in the cluster IV of the dendrogram instead of the cluster II in the PCoA.

The cluster IV consisted of nine genotypes in the PCoA plot, whereas it had eight genotypes in the dendrogram. The genotype 'Pazar-42' was an outgroup in the dendrogram, while 


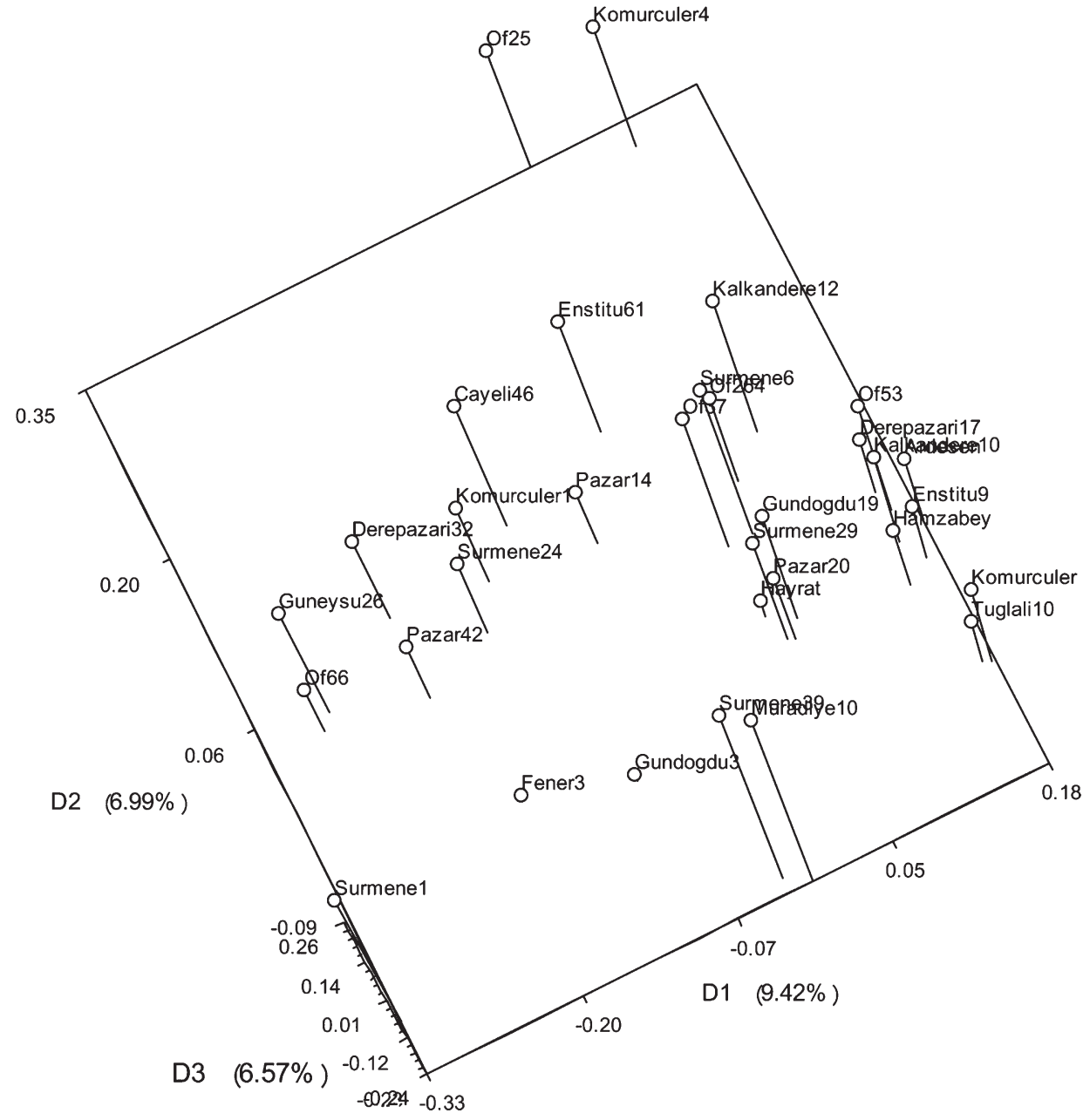

Fig. 2. Principal coordinate analysis of 32 tea genotypes, originating from the Trabzon and Rize provinces of Turkey, resulting from analysis of 835 AFLP markers.

this genotype was within the cluster IV in PCoA plot. In fact, this genotype has a tendency to dense flowering properties and high seed formation in contrast to the rest of the genotypes.

The cluster III included five genotypes ('Surmene-1', 'Surmene-39', 'Muradiye-10', 'Gundogdu-3', and 'Fener-3') dividing into two subclusters in the dendrogram and PCoA. 'Gundogdu-3' and 'Fener-3' formed first subcluster and the second subcluster included the rest of them. The closest pairs were 'Surmene-39'-'Muradiye-10' (0.88), 'Surmene-1'-'Surmene-39' (0.84), and 'Surmene-1'-'Muradiye-10' $(0.84)$ in this cluster.

In most cases, tea genotypes within the same cluster did not have similar morphological plant characteristics (Table 1; Fig. 1). For example, within the cluster II, the three pairs of genotypes that have a genetic similarity coefficient of 0.84 have different plant characteristics. For example, 'Hamzabey' has long, 'Tuglali-10' has medium, and 'Komurculer' has a small leaf size. Internode lengths, mature leaf colors, and leaf shapes are also different between these genotypes.

The same trend was also visible in the other clusters. Within the cluster IV, there were genotypes having intermediate ('Cayeli-46', 'Enstitu-61', 'Guneysu-26', and 'Komurculer1 '), long ('Derepazari-32'), and short ('Of-66', 'Of-264', and 'Surmene-24') internode lengths. Leaf shape also differed among the genotypes: 'Cayeli-46' had elliptical, 'Derepazari-32' had oblong, and 'Komurculer-1' had ovate leaf shapes. The same variation in morphological characteristics among the genotypes was also visible within the cluster III.

Genotypes sampled from the same location with similar names were not placed in the same cluster. For example, the genotypes from Of County of Trabzon Province were distributed within the cluster I ('Of-25'), cluster II ('Of-37' and 'Of-53'), and even the cluster IV ('Of-66' and 'Of-264'). The morphological characteristics of these genotypes also differed from each other, except in leaf color. Leaf pubescences of 'Of-25' and 'Of-53' genotypes were sparse; 'Of-37', 'Of-66', and 'Of-25' had intermediate leaf pubescence (Table 1). The genotypes selected from Surmene County showed similar results. According to the dendrogram obtained from AFLP data, 'Surmene-6' and 'Surmene-29' placed within the cluster II; 'Surmene-1' and 'Surmene-39' were in the cluster III; 'Surmene-24' was in the cluster IV (Fig. 1). The leaf size was medium in most of the genotypes; however, 'Surmene 39' exhibited large leaf size. 'Surmene-1', 'Surmene-29', and 'Surmene-39' had yellow-green, 'Surmene-6' had green, and 'Surmene-24' had gray-green leaf color (Table 1).

Dissimilarities in groupings using molecular markers or phenotaxonomic characteristics were also reported in strawberry [Fragaria ×ananassa (Garcia et al., 2002)], mulberry [Morus alba (Orhan et al., 2007)], and olive [Olea europaea (Hagidimitriou et al., 2005). These discrepancies were also previously reported by Zamani et al. (2007), who compared data from the genetic distance matrices obtained from RAPD markers and from fruit characteristics in pomegranate. Their correlation coefficient, for comparison of morphological and RAPD data, was only $23 \%$. These results support the view that morphological characteristics are not reliable for estimating genetic relationships among large and diverse groups of genotypes, and should be used mainly for discrimination.

These results may be expected when we consider the starting point of tea cultivation in Turkey. It was started in 1938 by establishing a new plantation in the eastern part of the Rize Province by providing seeds from Batumi (Georgia); the plantations was then expanded from the Rize to the Trabzon, Artvin, Giresun, and Ordu provinces (Beris et al., 2005). In tea cultivar breeding programs, estimates of genetic relationships can be useful for the identification of parents for crossing and reducing the number of genotypes needed to maintain sufficient genetic variation. Further study is needed to increase genetic 
diversity in Turkish tea germplasm by introducing new genotypes from diverse locations in Turkey and especially from the other germplasms in the world, which will create a broad range of genetic variation in the future tea breeding programs.

In conclusion, we have, for the first time, employed AFLP for the assessment of genetic diversity of Turkish tea genotypes; AFLP successfully detected polymorphism and genetic relationships among Turkish tea genotypes. The UPGMA dendrogram of AFLP bands even separated the closely related tea genotypes. The results of the present study may benefit breeders in selecting the most diverse genotypes with favorable characteristics to start crossing and selection programs.

\section{Literature Cited}

Altindal, E. and F. Balta. 2002. Comparison of rooting capabilities of Turkish tea clones. Turkish J. Agr. For. 26:1995-2001.

Ariyarathna, C. and K. Gunasekare. 2006. Genetic base of tea (Camellia sinensis L.) cultivars in Sri Lanka as revealed by pedigree analysis. J. Appl. Genet. 48:125-128.

Balasaravanan, T., P.K. Pius, R.R. Kumar, N. Muraleedharan, and A.K. Shasany. 2003. Genetic diversity among south Indian tea germplasm (Camellia sinensis, C. assamica and C. assamica ssp. lasiocalyx) using AFLP markers. Plant Sci. 165:365-372.

Beris, F.S., C. Sandalli, S. Canakci, Z. Demirbag, and A.O. Belduz. 2005. Phylogenetic analysis of tea clones (Camellia sinensis) using RAPD markers. Biologia 60:457-461.

Chang, H.T. 1984. A revision of the tea resource plants. Acta Sci. Natur. Univ. Sunyatseni 106:1-12.

Chen, L. and S. Yamaguchi. 2005. RAPD markers for discriminating tea germplasm at the inter-specific level in China. Plant Breed. 124:404-409.

Chen, L., F.L. Yu, and Q.Q. Tong. 2000. Discussions on phylogenetic classification and evolution of sect Thea. J. Tea Sci. 20:89-94.

Chen, L., Q.K. Gao, D.M. Chen, and C.J. Xu. 2005. The use of RAPD markers for detecting genetic diversity, relationship and molecular identification of Chinese elite tea genetic resources [Camellia sinensis (L.) O. Kuntze] preserved in a tea germplasm repository. Biodivers. Conserv. 14:1433-1444.

Devarumath, R.M., S. Nandy, V. Rani, S. Marimuthu, N. Muraleedharan, and S.N. Raina. 2002. RAPD, ISSR and RFLP fingerprints as useful markers to evaluate genetic integrity of micropropagated plants of three diploid and triploid elite clones representing Camellia sinensis (China type) and C. assamica ssp. assamica (Assam-India type). Plant Cell Rep. 21:166-173.

Doyle, J.J. and J.L. Doyle. 1987. A rapid isolation procedure for small quantities of fresh leaf tissue. Phytochem. Bul. 19:11-15.

Ercisli, S., E. Orhan, O. Ozdemir, M. Sengul, and N. Gungor. 2008. Seasonal variation of total phenolic, antioxidant activity, plant nutritional elements, and fatty acids in tea leaves (Camellia sinensis var. sinensis clone Derepazari 7) grown in Turkey. Pharmaceutical Biol. 46:683-687.

Erturk, Y., S. Ercisli, R. Sekban, A. Haznedar, and M.F. Donmez. 2008. The effect of plant growth promoting rhizobacteria (PGPR) on rooting and root growth of tea (Camellia sinensis var. sinensis) cuttings. Romanian Biotechnol. Lett. 13:33-43.

Food and Agricultural Organization of the United Nations. 2007. Agriculture data. 14 Nov. 2008. <http://www.faostat.fao.org/site/ 567/default.aspx>.

Garcia, M.G., M. Ontivero, J.C. Diaz Ricci, and A. Castagnaro. 2002. Morphological traits resolution RAPD markers for the identification of the main strawberry varieties cultivated in Argentina. Plant Breed. 121:76-80.

Hagidimitriou, M., A. Katsiotis, G. Menexes, C. Pontikis, and M. Loukas. 2005. Genetic diversity of major Greece olive cultivars using molecular (AFLPs and RAPDs) markers and morphological traits. J. Amer. Soc. Hort. Sci. 130:211-217.
Hung, C.Y., K.H. Wang, C.C. Huang, X. Gong, X.J. Ge, and T.Y. Chiang. 2008. Isolation and characterization of 11 microsatellite loci from Camallia sinensis in Taiwan using PCR-based isolation of microsatellite arrays. Conserv. Genet. 9:779-781.

Kafkas, S., H. Ozkan, B.E. Ak, I. Acar, H.S. Atli, and S. Koyuncu. 2006. Detecting DNA polymorphism and genetic diversity in a wide pistachio germplasm: Comparison of AFLP, ISSR and RAPD markers. J. Amer. Soc. Hort. Sci. 131:522-529.

Kafkas, S., M. Ozgen, Y. Dogan, B. Ozcan, S. Ercisli, and S. Serce. 2008. Molecular characterization of mulberry accessions in Turkey by AFLP markers. J. Amer. Soc. Hort. Sci. 133:593-597.

Karthigeyan, S., S. Rajkumar, R. Sharma, A. Gulati, R. Sud, and P. Ahuja. 2008. High level of genetic diversity among the selected accessions of tea (Camellia sinensis) from abandoned tea gardens in Western Himalaya. Biochem. Genet. 46:810-819.

Kaundun, S.S., A. Zhyvoloup, and Y.G. Park. 2000. Evaluation of the genetic polymorphism among elite tea (Camellia sinensis var. sinensis) accessions using RAPD markers. Euphytica 115: $7-16$.

Kaundun, S.S. and S. Matsumoto. 2003. Identification of processed Japanese green tea based on polymorphisms generated by STS-RFLP analysis. J. Agr. Food Chem. 51:1765-1770.

Kaundun, S.S. and Y.G. Park. 2002. Genetic structure of six Korean tea populations as revealed by RAPD-PCR markers. Crop Sci. 42:594601.

Lee, S., J. Kim, J. Sano, Y. Ozaki, and H. Okubo. 2003. Phylogenetic relationships among tea cultivars based on AFLP analysis. J. Fac. Agr Kyushu Univ. 47:289-299.

Mantel, N. 1967. The detection of disease clustering and a generalized regression approach. Cancer Res. 27:175-178.

Matsumoto, S., Y. Kiriiwa, and Y. Takeda. 2002. Differentiation of Japanese green tea cultivars as revealed by RFLP analysis of phenylalanine ammonia-lyase DNA. Theor. Appl. Genet. 104:9981002 .

Mondal, T.K. 2002. Assessment of genetic diversity of tea (Camellia sinensis (L.) O. Kuntze) by inter-simple sequence repeat polymerase chain reaction. Euphytica 128:307-315.

Ohsako, T., T. Ohgushi, H. Motosugi, and K. Oka. 2008. Microsatellite variability within and among local landrace populations of tea, Camellia sinensis (L.) O. Kuntze, in Kyoto, Japan. Genet. Resources Crop Evol. 55:1047-1053.

Oksuz, M. 1987. Morphological, yield and quality properties of tea clones in Turkey. Çay İşletmeleri Genel Müdürlüğü, Caykur, Rize, Turkey, No. 8.

Orhan, E., S. Ercisli, N. Yildirim, and G. Agar. 2007. Genetic variations among mulberry genotypes (Morus alba) as revealed by random amplified polymorphic DNA (RAPD) markers. Plant Syst. Evol. 265:251-258.

Park, Y.G., S.S. Kaundun, and A. Zhyvoloup. 2002. Use of the bulked genomic DNA-based RAPD methodology to assess the genetic diversity among abandoned Korean tea plantations. Genet. Resources Crop Evol. 49:159-165.

Paul, S., F.N. Wachira, W. Powell, and R. Waugh. 1997. Diversity and genetic differentiation among populations of Indian and Kenyan tea (Camellia sinensis (L.) O. Kuntze) revealed by AFLP markers. Theor. Appl. Genet. 94:255-263.

Prevost, A. and M.J. Wilkinson. 1999. A new system of comparing PCR primers applied to ISSR fingerprinting of potato cultivars. Theor. Appl. Genet. 98:107-112.

Rohlf, F.J. 2004. NTSYS-pc numerical taxonomy and multivariate analysis system. Version 2.11V. Exeter Software, Setauket, NY.

Smith, J.S.C., E.C.L. Chin, H. Shu, O.S. Smith, S.J. Wall, M.L. Senior, S.E. Mitchell, S. Kresovich, and J. Ziegle. 1997. An evaluation of the utility of SSR loci as molecular markers in maize (Zea mays L.): Comparisons with data from RFLPs and pedigree. Theor. Appl. Genet. 95:163-173.

Thomas, J., D. Vijayan, S.D. Joshi, S.J. Lopez, and R.R. Kumar. 2006. Genetic integrity of somaclonal variants in tea [Camellia sinensis 
(L.) O Kuntze] as revealed by inter simple sequence repeats. J. Biotechnol. 123:149-154.

Vos, P., L. Hogers, M. Bleeker, T. Van De Lee, M. Hornes, A. Frijters, J. Pot, J. Peleman, M. Kuiper, and M. Zabeau. 1995. AFLP: A new technique for DNA fingerprinting. Nucleic Acids Res. 23:44074414.

Wachira, F.N., J. Tanaka, and Y. Takeda. 2001. Genetic variation and differentiation in tea (Camellia sinensis) germplasm revealed by RAPD and AFLP variation. J. Hort. Sci. Biotechnol. 76:557563.
Wachira, F.N., R. Waugh, C.A. Hackett, and W. Powell. 1995. Detection of genetic diversity in tea (Camellia sinensis) using RAPD markers. Genome 38:201-210.

Yao, M.Z., L. Chen, and Y.R. Liang. 2008. Genetic diversity among tea cultivars from China, Japan and Kenya revealed by ISSR markers and its implication for parental selection in tea breeding programmes. Plant Breed. 127:166-172.

Zamani, Z., A. Sarkhosh, R. Fatahi, and A. Ebadi. 2007. Genetic relationships among pomegranate genotypes studied by fruit characteristics and RAPD markers. J. Hort. Sci. Biotechnol. 82:11-18. 